\title{
Materials for the Hydrogen Economy
}

Depending on the availability and the cost of fossil fuels, as well as on political factors, the encouragement to the development of hydrogen energy related technologies varies in intensity. It has been five years since the creation of the International Partnership for the Hydrogen Economy (IPHE) - Sixteen countries and the European Community, as well as Brazil, integrate the IPHE - it has been a great support for research and development works about hydrogen energies. Nowadays, considering that several prognostics for practical application made at that time were not achieved, that a crisis has occurred, and, furthermore, that some governments of IPHE member countries were changed, an important decrease on investment in this area is experienced in some countries, especially those from North America, Asia and some Europeans ones, such as France. However, in Europe, the German investments persist very important and continuous and Brazil is evaluating the situation, with prospects to keep on with the actions of the $\mathrm{ProH} 2$ Program, belonging to the Ministry of Science and Technology.

One of the key points for the developments mentioned is the conception, the optimization and the suitability to the utilization conditions of the new materials. These include those used as electrolyte, electrodes, current collecting sheets and sealing materials for fuel cells and also materials for hydrogen storage and those used in other parts of the system, which must present mechanical resistance and resistances to corrosion, fatigue and hydrogen embrittlement, depending on the application. Some articles in this and the next edition approach themes related to this area.

Cordially,

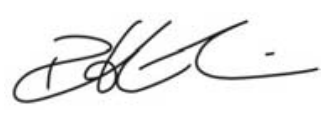

Paulo Emílio V. de Miranda

Editor-in-Chief 